\title{
Cardiac magnetic resonance imaging and computed tomography in ischemic cardiomyopathy: an update*
}

\author{
Ressonância magnética cardíaca e tomografia computadorizada na cardiomiopatia isquêmica: \\ atualidades
}

Fernanda Boldrini Assunção ${ }^{1}$, Diogo Costa Leandro de Oliveira $^{1}$, Vitor Frauches Souza ${ }^{2}$, Marcelo Souto Nacif ${ }^{3}$

Assunção FB, Oliveira DCL, Souza VF, Nacif MS. Cardiac magnetic resonance imaging and computed tomography in ischemic cardiomyopathy: an update. Radiol Bras. 2016 Jan/Fev; 49(1):26-34.

\begin{abstract}
Ischemic cardiomyopathy is one of the major health problems worldwide, representing a significant part of mortality in the general population nowadays. Cardiac magnetic resonance imaging (CMRI) and cardiac computed tomography (CCT) are noninvasive imaging methods that serve as useful tools in the diagnosis of coronary artery disease and may also help in screening individuals with risk factors for developing this illness. Technological developments of CMRI and CCT have contributed to the rise of several clinical indications of these imaging methods complementarily to other investigation methods, particularly in cases where they are inconclusive. In terms of accuracy, CMRI and CCT are similar to the other imaging methods, with few absolute contraindications and minimal risks of adverse side-effects. This fact strengthens these methods as powerful and safe tools in the management of patients. The present study is aimed at describing the role played by CMRI and CCT in the diagnosis of ischemic cardiomyopathies.
\end{abstract}

Keywords: Ischemic cardiomyopathy; Heart; Magnetic resonance imaging; Computed tomography.

Resumo A cardiomiopatia isquêmica é um dos principais problemas de saúde no mundo, representando significativa parcela da mortalidade. A ressonância magnética cardíaca (RMC) e a tomografia computadorizada cardíaca (TCC) são métodos de imagem não invasivos úteis no diagnóstico da doença arterial coronariana e também podem auxiliar no rastreamento de indivíduos com fatores de risco para o desenvolvimento de cardiomiopatia induzida por isquemia/infarto. Os avanços tecnológicos da RMC e da TCC contribuíram para o surgimento de diversas indicações clínicas para aplicação desses métodos de imagem de forma complementar a outros exames, principalmente quando estes se mostram inconclusivos. A RMC e a TCC apresentam acurácia semelhante aos demais métodos de imagem, poucas contraindicações absolutas e mínimos riscos de efeitos adversos, o que os fortalecem como ferramentas seguras no manejo dos pacientes. O presente estudo tem por objetivo descrever o papel da RMC e da TCC no diagnóstico das cardiomiopatias isquêmicas.

Unitermos: Cardiomiopatia isquêmica; Coração; Ressonância magnética; Tomografia computadorizada.

\section{INTRODUCTION}

Ischemic cardiomyopathy is one of the major health problems worldwide, playing a significant role in the mortality nowadays. It is a condition characterized by the presence of myocardial ischemia, either associated or not with fibrosis caused by myocardial infarction. Myocardial ischemia only occurs in cases of imbalance between oxygen supply and demand, and the decreased blood flow is considered to be the physiopathology in most cases of acute myocardial infarction and unstable angina episodes. Additionally, the syn-

* Study developed at Department of Radiology of School of Medicine - Universidade Federal Fluminense (UFF), Niterói, RJ, Brazil. Financial support: Fundação Carlos Chagas Filho de Amparo à Pesquisa do Estado do Rio de Janeiro (Faperj) and Conselho Nacional de Desenvolvimento Científico e Tecnológico (CNPq).

1. MDs, Trainees at School of Medicine - Universidade Federal Fluminense (UFF), Niterói, RJ, Brazil.

2. MD, Resident of Magnetic Resonance Imaging and Emergency Radiology at Complexo Hospitalar de Niterói (CHN), Niterói, RJ, Brazil.

3. Associate Professor and Vice-Chief of the Department of Radiology, School of Medicine - Universidade Federal Fluminense (UFF), Niterói, RJ, Brazil.

Mailing Address: Dr. Marcelo Souto Nacif. Rua Barão de Cocais, 324, Bosque Imperial. São José dos Campos, SP, Brazil, 12242-042. E-mail: msnacif@gmail.com / unw.msnacif.med.br.

Received June 19, 2014. Accepted after revision October 6, 2014. ergism between the oxygen supply and demand is the main determining factor of ischemia in cases of stable chronic angina $^{(1)}$.

The clinical presentation of the coronary disease ranges from stable chronic angina to sudden death. This spectrum includes acute myocardial infarction with ST segment elevation, acute myocardial infarction without ST segment elevation, and unstable angina, currently catalogued as acute coronary syndrome ${ }^{(1)}$. In about $50 \%$ to $70 \%$ of patients, acute myocardial infarction is the first manifestation of ischemic cardiomyopathy ${ }^{(2,3)}$. The main etiopathogenic substrate of ischemic cardiomyopathies is atherosclerosis ${ }^{(4)}$. The risk factors for development of atherosclerosis and subsequent ischemic cardiomyopathy include, besides age, systemic arterial hypertension, diabetes mellitus, smoking, dyslipidemia, sedentarism and obesity ${ }^{(5)}$.

The diagnosis is based on the patient's clinical history and presence of risk factors. Electrocardiography and chest radiography may also be useful to clarify chest pain etiology. Cardiac catheterization, however, is the gold standard for the diagnosis of coronary artery disease (CAD), despite its invasiveness and expensiveness ${ }^{(6)}$. Currently, noninvasive 
cardiac imaging has been fundamental for the diagnosis and management of patients with diagnosis or even suspicious of chronic coronary disease ${ }^{(7)}$. Most frequently, the following noninvasive methods are utilized in the diagnosis of ischemic cardiomyopathy: exercise stress test; pharmacological stress or exercise stress echocardiography; myocardial perfusion scintigraphy; cardiac magnetic resonance imaging (CMRI); and cardiac computed tomography (CCT), with emphasis on the two latter methods ${ }^{(1)}$.

CMRI is extremely useful in the evaluation of CAD, both in the acute and chronic phases. Because of its high spatial resolution, this method can currently be considered as a reference standard for evaluation of the global and regional myocardial function and for detection and quantification of myocardial infarction areas ${ }^{(7,8)}$. CCT is a more recent method with main clinical application focused on the diagnosis of CAD, determining the Agatston coronary calcium score (CCS) and the performance of noninvasive coronary angiography ${ }^{(7,8)}$.

On the basis of the above considerations, the present study is aimed at describing the current concepts regarding the utilization of CMRI and CCT in ischemic cardiomyopathy, highlighting the diagnostic, therapeutic and prognostic impacts caused by the method. A systematic review was performed in the PubMed data basis sources (National Library of Medicine), utilizing the search terms "cardiac magnetic resonance in ischemic cardiomyopathy" and "computed tomography in ischemic cardiomyopathy", as well as in themecorrelated books, consensus and societies guidelines.

\section{RESULTS}

The authors found 1319 articles and, among those, 43 articles published in high-impact journals were selected by consensus of the authors, Additionally one societies consensus and three guidelines (I Diretriz de Ressonância e Tomografia Cardiovascular da Sociedade Brasileira de Cardiologia $^{(8)}$, III Diretriz Brasileira de Insuficiência Cardíaca Crônica ${ }^{(9)}$ and Diretriz de Doença Coronariana Crônica Angina Estável $\left.{ }^{(10)}\right)$ were utilized. The present study was developed on the data collected in this review.

\section{DISCUSSION}

\section{Cardiac magnetic resonance imaging (CMRI)}

CMRI allows for evaluating the global and regional myocardial function, detecting and quantifying areas of myocardial infarction without utilizing ionizing radiation and nephrotoxic contrast agents, being one of the most safe methods in cardiovascular diagnosis ${ }^{(8)}$. Because of the obtention of ventricular volumes and masses by means of a tridimensional approach, CMRI has high accuracy in the obtention of values for both the left ${ }^{(11)}$ and right ${ }^{(12)}$ ventricles, and is considered to be the gold standard for such measurements ${ }^{(7)}$. Non contrast-enhanced echocardiography underestimates the ejection fraction values and volumes as compared with $\mathrm{CMRI}^{(13)}$. Additionally, CMRI is useful to visualize and characterize cardiac masses and thrombi, evaluate the valve function, and demonstrate with high resolution the complex processes of both congenital and acquired cardiovascular diseases $^{(7)}$. It may also be utilized in the evaluation of the ventricular anatomy, ventricular aneurysms, pericarditis, and in the postoperative follow-up to evaluate the improvement in the cardiac function ${ }^{(14,15)}$.

\section{Assessment of global and segmental function}

CMRI provides accurate and highly reproducible data regarding parameters of mass, volume, and global and regional contractility of right and left ventricles ${ }^{(8)}$ (Figure 1). The evaluation of the regional left ventricle function (segmental contractility) is performed both at rest and under pharmacological stress. The results of the segmental contractility analysis by means of CMRI are superior to those from echocardiography ${ }^{(16)}$. The most utilized techniques for investigating the presence of CAD involve the direct visualization of effects from ischemia, induced by pharmacological stress, and a multimodal analysis of the segmental contractility and myocardial perfusion. CMRI presents the unique characteristic of providing both types of information in a single procedure, combining the higher specificity in the evaluation of the regional function under stress with the higher sensitivity in the assessment of the myocardial perfu$\operatorname{sion}^{(8)}$.

\section{Assessment of myocardial perfusion}

The assessment of myocardial perfusion (Figure 2) is performed at rest and under pharmacological stress (dipyridamole or adenosine) and is analyzed together with the delayed enhancement images to identify necrotic or fibrotic areas ${ }^{(8)}$. CMRI with myocardial perfusion has excellent sensitivity and specificity as compared with cardiac catheterization $^{(17,18)}$. CMRI has already been validated utilizing the methods currently available in the cardiological practice with comparative analyses and longitudinal evaluation for prognostic characterization of patients. Currently, the clinical utilization of this method is already quite consolidated ${ }^{(19)}$. As the myocardial perfusion evaluated by CMRI under stress is normal, the patient presents with a low rate of future cardiovascular events. On the other hand, in the presence of ischemia, the rate of future cardiovascular events is high, thus determining its prognostic capacity ${ }^{(20)}$.

\section{Evaluation of delayed myocardial enhancement}

The protocols based on delayed myocardial gadolinium enhancement allow for accurate delimitation of the areas of myocardial necrosis or fibrosis in patients with chronic ${ }^{(8)}$ and acute ${ }^{(7)}$ infarction. The technique is based on the gadolinium property of extracellular distribution between the normal and infarcted/fibrotic tissues, with a much slower output from the latter, which generates a longer lasting contrast medium accumulation in those tissues. This allows for an evaluation of the delayed myocardial enhancement as there 

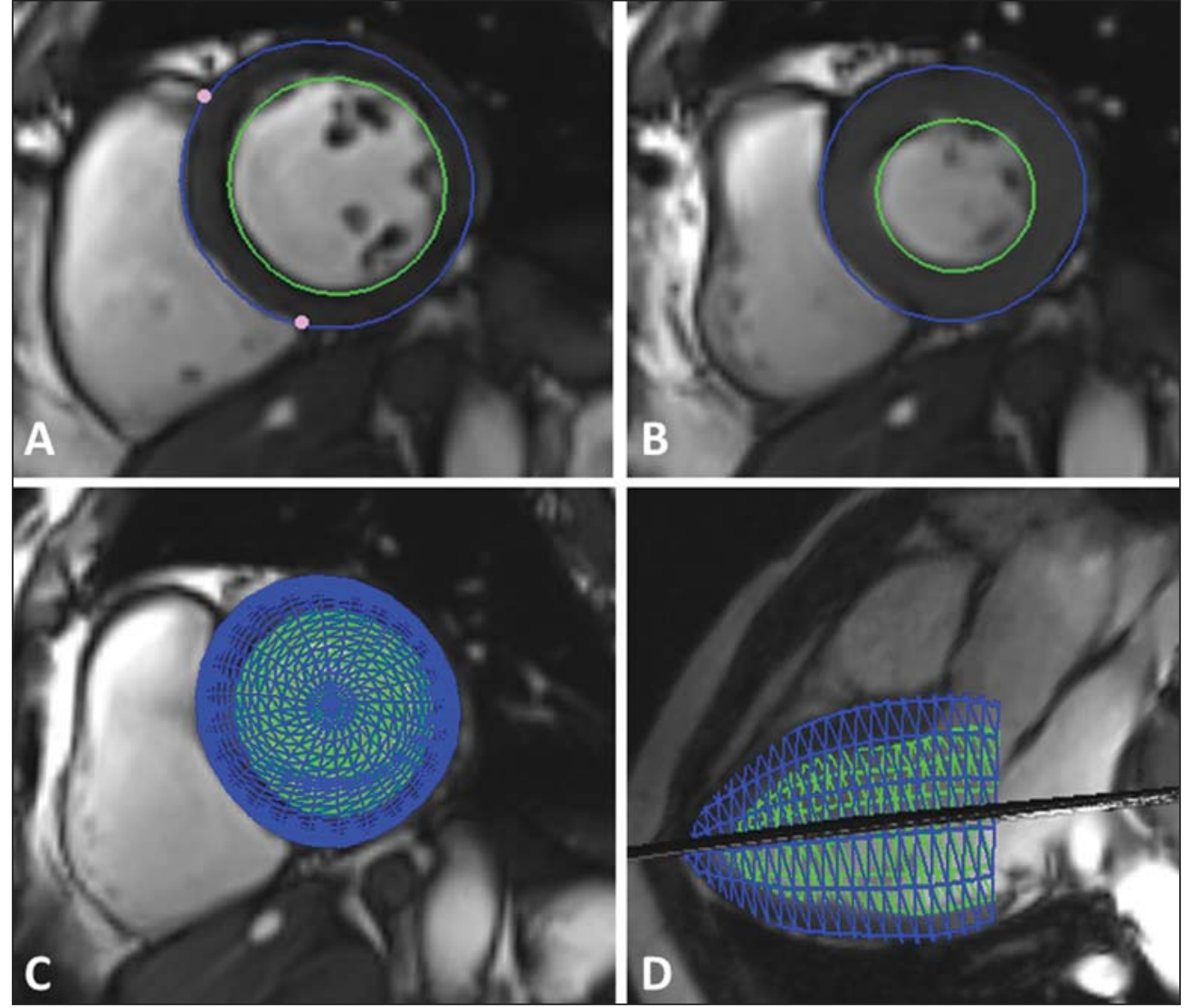

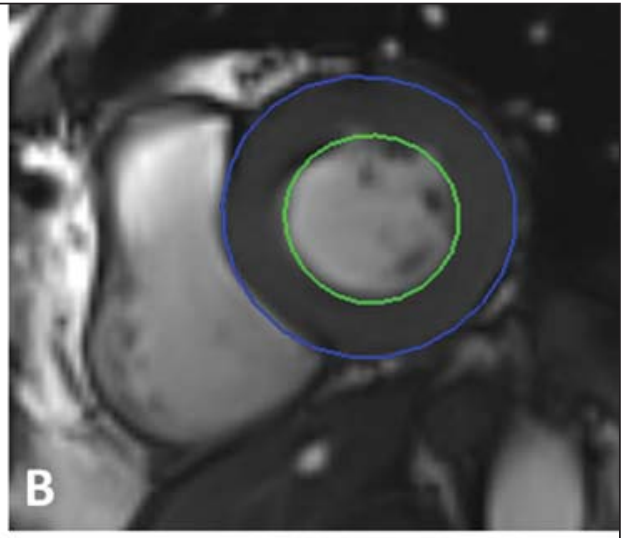

Figure 1. Ventricular function evaluation. Simpson's technique $(\mathbf{A}, \mathbf{B})$ and 4D (C,D).

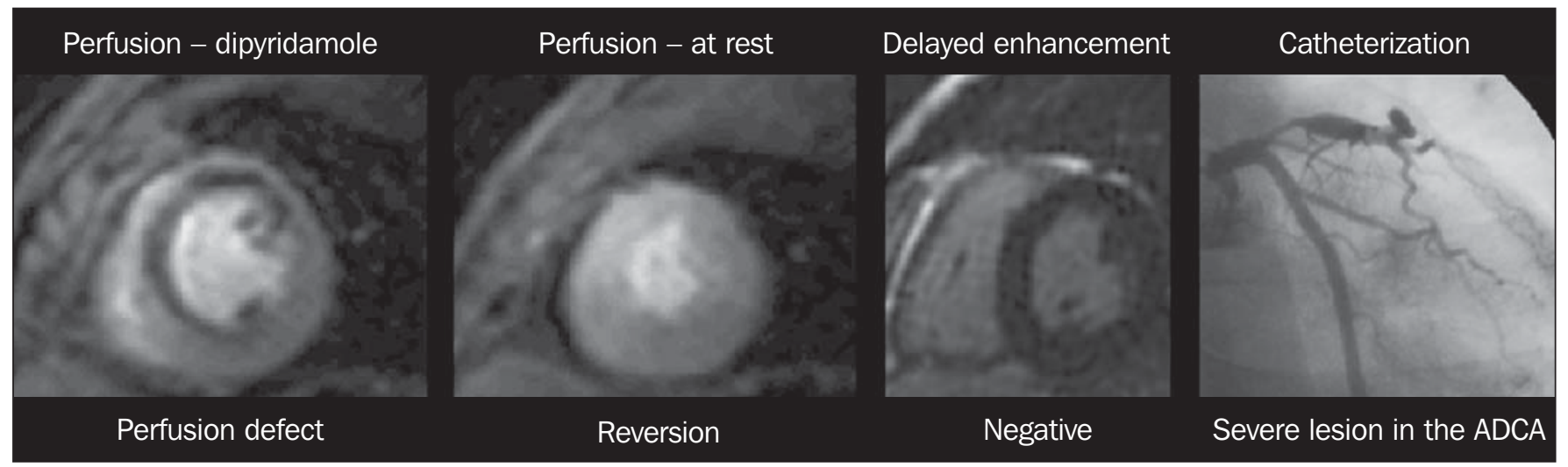

Figure 2. Evaluation of myocardial perfusion under pharmacological stress and at rest. ADCA, anterior descending coronary artery.

is a clear signal difference between the two tissues (black/ white $)^{(8)}$ (Figure 3).

In what concerns $\mathrm{CAD}$, the presence and the pattern of delayed myocardial enhancement at CMRI in a patient with ventricular dysfunction allows for the diagnosis of ischemic or non-ischemic cardiomyopathy ${ }^{(7)}$. The evaluation of transmurality of the regions with myocardial necrosis or fibrosis allows for predicting, with excellent accuracy, the probability of regional myocardial function recovery after revascularization, either surgical or percutaneous ${ }^{(21)}$. As a function of its excellent spatial resolution, CMRI can diagnose, besides transmural infarction, small subendocardial infarctions ${ }^{(8)}$. Cine CMRI allows for the same type of analysis of segmental contractility than echocardiography. However, as such information is combined with the detailed evaluation of the infarcted region provided by the delayed myocardial enhancement technique, CMRI allows for accurately determining what is stunned myocardial tissue and what is irreversible necrosis ${ }^{(8)}$.

\section{Contraindications and limitations}

CMRI has some relative contraindications, namely, presence of pacemakers, implanted defibrillators, cerebral clips, cochlear implants and metal fragments in the eyes ${ }^{(8)}$. Among the method limitations, there is the fact that coronary MRI angiography, employing several acquisition techniques, re- 
Figure 3. Evaluation of delayed myocardial enhancement. Normal study, black muscle (A). Myocardial infarction, white areas (B).
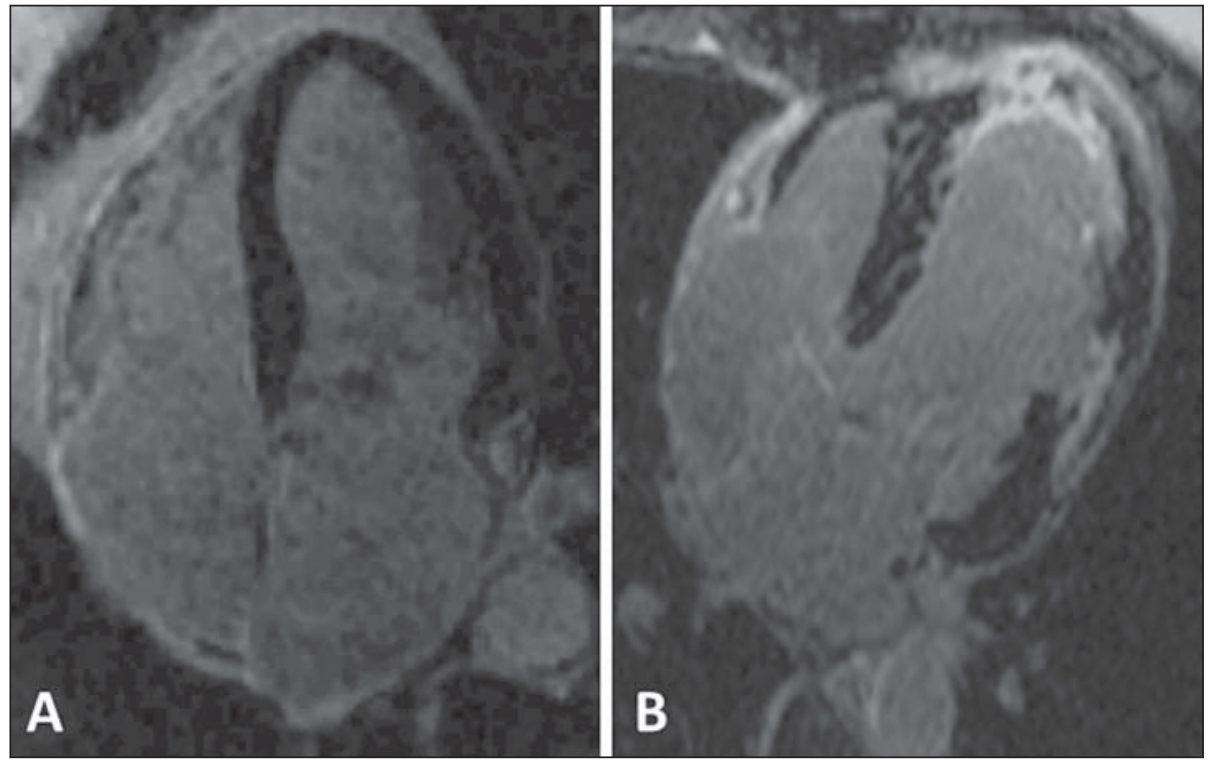

veals moderate sensitivity $(72-77 \%)$ and specificity $(71-87 \%)$ values for detection of coronary stenosis as compared with invasive angiography ${ }^{(22,23)}$. CMRI has modest spatial resolution in the detection of coronary stenosis as compared with the high spatial resolution provided by CCT. It is possible that in the future coronary MRI becomes more usual, but currently, coronary CT angiography is a more robust method, with higher sensitivity and specificity as compared with CMRI ${ }^{(23)}$.

The method limitations include systemic nephrogenic fibrosis, a disease that causes systemic tissue fibrosis and is associated with the use of gadolinium in patients with chronic renal failure stages 4 and 5 and in patients with hepatorenal syndrome. It is important to highlight that such warning does not apply to patients with normal renal function. The systemic nephrogenic fibrosis physiopathogenesis is still to be understood, but it is known that there is an association between the development of the disease and use of gadolinium, which was demonstrated by the detection of gadolinium in biopsies of tissues of patients with systemic nephrogenic fibrosis, and by the disease onset after a 2-12-week period after the use of gadolinium. Systemic nephrogenic fibrosis is a quick-onset and progressive condition, determining the onset of symptoms such as muscle weakness, arthralgia, skin hardening and contractures, which, in conjunction, lead to the patient immobility. The risk for development of the disease increases at each exposure to gadolinium. For this reason, the Food and Drug Administration recommends the calculation of the creatinine clearance in the patients previously to the gadolinium enhanced CMRI, and the indication of this examination for patients at risk only if strictly necessary, followed by dialysis, despite the absence of scientific evidence that dialysis prevents the onset of systemic nephrogenic fibrosis ${ }^{(24)}$.

In the clinical practice, all the imaging studies for investigation of ischemia are performed with the patient un- der pharmacological stress, which represents a partial limitation for the non-pharmacological evaluation, in spite of the fact that some studies have already demonstrated the possibility of performing MRI with exercise stress ${ }^{(25)}$.

\section{Cardiac computed tomography (CCT)}

CCT is a method that utilizes ionizing radiation and iodinated contrast agent, with the main clinical application focused on the diagnosis of $\mathrm{CAD}^{(26)}$. Such method presents a high negative predictive value in the detection of $\mathrm{CAD}^{(9)}$, and for this reason it may be utilized as an alternative to cardiac catheterization to rule out $\mathrm{CAD}^{(27)}$.

\section{Coronary calcium score}

CCT detects and quantifies coronary artery calcium, a marker of the presence and extent of atherosclerotic disease $^{(8)}$. The presence of calcium in the coronary arteries have a strong predictive value for future cardiac events in asymptomatic patients ${ }^{(28-30)}$, considering the high probability of obstructive coronary disease associated with the increase in the amount of coronary calcium ${ }^{(30,31)}$. Thus evaluation based on the CCS allows for the differentiation between asymptomatic patients and those under risk to develop CAD over time $^{(7)}$. At the Bethesda Conference, it was concluded that CCT and the CCS technique constitute the most accurate method currently available for early detection of coronary atherosclerosis $^{(7)}$.

Despite the wide applicability of the CCS, it is important to highlight that, in some situations, obstructive lesions might not contain calcium, and calcified lesions might not be obstructive ${ }^{(32)}$. Such process is explained by the Gagov's phenomenon $^{(23)}$ that consists in the patency of the normal volume of the vessel, despite the presence of an atherosclerotic process, which is called positive remodelling. The evaluation of the CCS (Figure 4) is complementarily added to the clinical risk stratification data, with possibility to add 

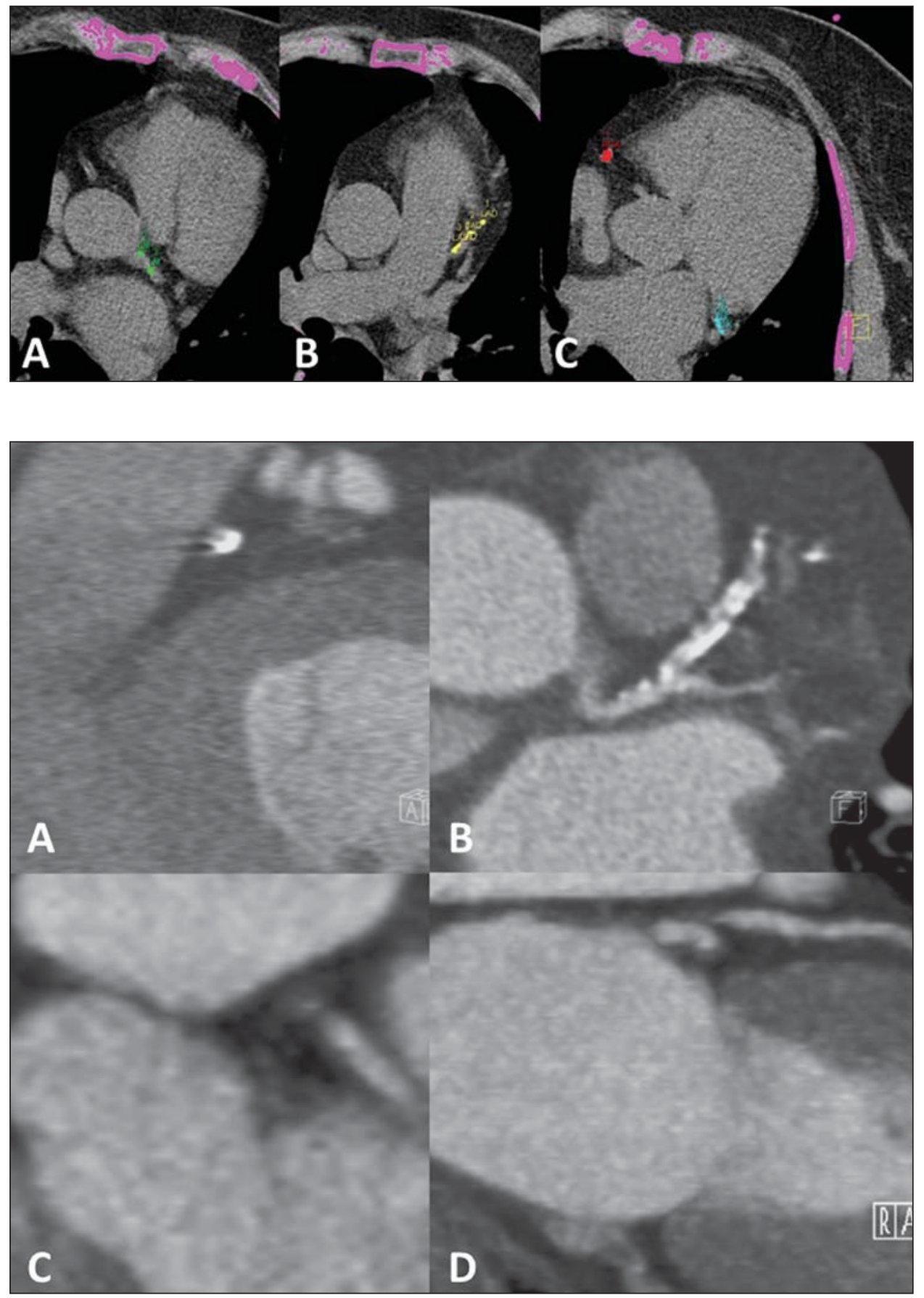

Figure 4. Evaluation of coronary calcium score. Left coronary trunk, green (A). Proximal third of the anterior descending coronary artery, yellow (B). Right coronary artery, red, and circumflex coronary artery, light blue (C).
Figure 5. Evaluation of the vessel wall and composition of atheromatous plaques with luminal reduction by calcified plaque $(\mathbf{A}, \mathbf{B})$ and by noncalcified plaque $(\mathbf{C}, \mathbf{D})$. clinical conducts, principally for patients considered to be at intermediate risk by the Framingham scores ${ }^{(33,34)}$ and by the percentile stratified by the Multi-Ethnic Study of Atherosclerosis $^{(35)}$.

\section{Coronary computed tomography angiography}

Besides the coronary calcium evaluation, CCT may be used as a noninvasive modality of coronary angiography, which is called coronary computed tomography angiography (CCTA), with high sensitivity and specificity in the detection of coronary stenosis. It is indicated principally for patients at intermediate risk for CAD and with dubious tests for ischemia, or in patients with low clinical probability of CAD, but with positive test for ischemia ${ }^{(8)}$. CCTA is performed by means of multidetector CT, preferentially with 64 or more channels, under a single apnea. Routinely, the amount of contrast agent utilized is between 70 and $100 \mathrm{~mL}$, which is considered to be low, therefore reducing the occurrence of problems associated with nephrotoxicity. CCTA is capable of visualizing the vessel volume and walls, which allows for a noninvasive evaluation of the presence and size of noncalcified plaques ${ }^{(7)}$ (Figure 5). In the evaluation of intra-stent restenosis in general, CCTA diagnostic accuracy is accepted as sufficient for clinical use in a noninvasive 
Figure 6. Evaluation of neointimal hyperplasia with intra-stent restenosis. Transversal axis (A) and longitudinal axis (B).

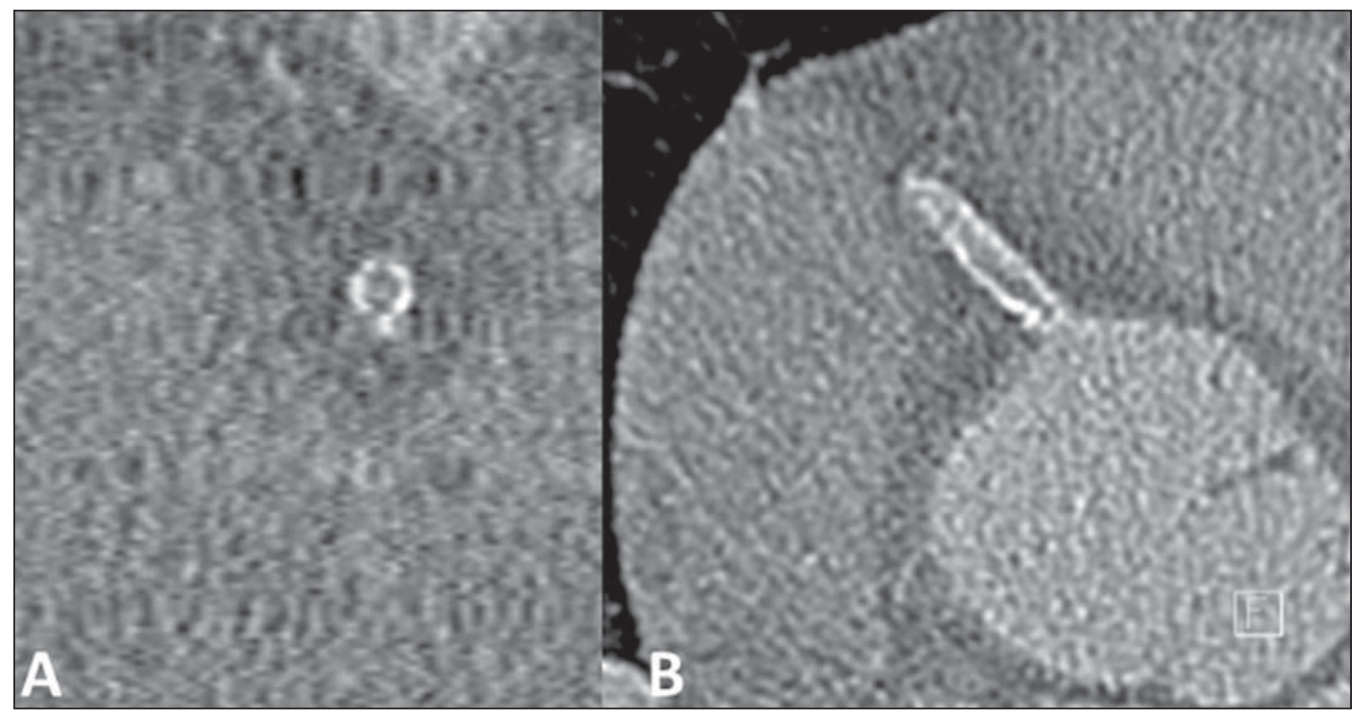

Figure 7. Evaluation of left internal mammary artery graft to anterior descending coronary artery (DA). Note the route of the graft in the mediastinum $(\mathbf{A})$ and the anastomosis of the permeable graft (double asterisks) with the native anterior descending artery (single asterisk) (B).
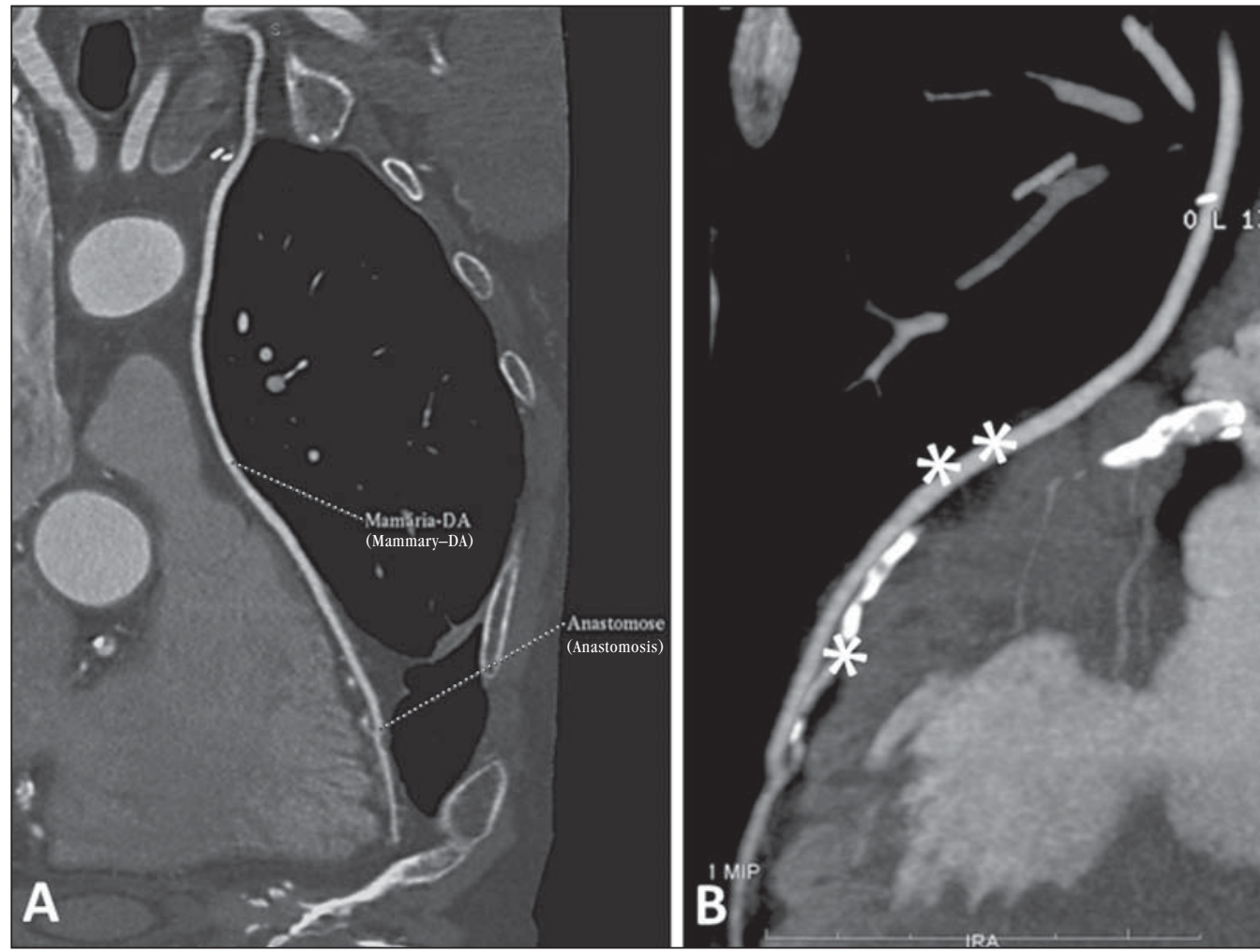

method, depending on the utilized method ${ }^{(36,37)}$ (Figure 6). The method can still be utilized to evaluate the patency of surgical grafts or for differentiation between ischemic and non-ischemic cardiomyopathy ${ }^{(8)}$ (Figures 7 and 8).

\section{Contraindications and limitations}

The main CCTA limitation occurs in the presence of dense calcification in the coronary arteries or the presence of a bare metal stent. In both situations, it will not possible to evaluate the degree of luminal obstruction. Another limitation is the necessity of a low heart rate $(<70 \mathrm{bpm})$, requiring the use of beta-blockers during the scan. The use of sub- lingual nitrate, as indicated, might be considered as a limiting factor as it generates a tendency to the CCTA overestimate the degree of coronary stenosis ${ }^{(38,39)}$, which frequently leads to the necessity for confirmation by means of a myocardial function test. The utilization of radiation is also considered to represent a limitation of the method ${ }^{(7)}$, but, with the recent technological developments, radiation doses have been reduced. Additionally, iodine-based contrast agents utilized in CCTA are nephrotoxic, differently from the gadoliniumbased ones utilized in CMRI. However, such a nephrotoxicity is usually self-limited and severe allergic reactions rarely occur. Preventive measures in relation to nephrotoxicity may 

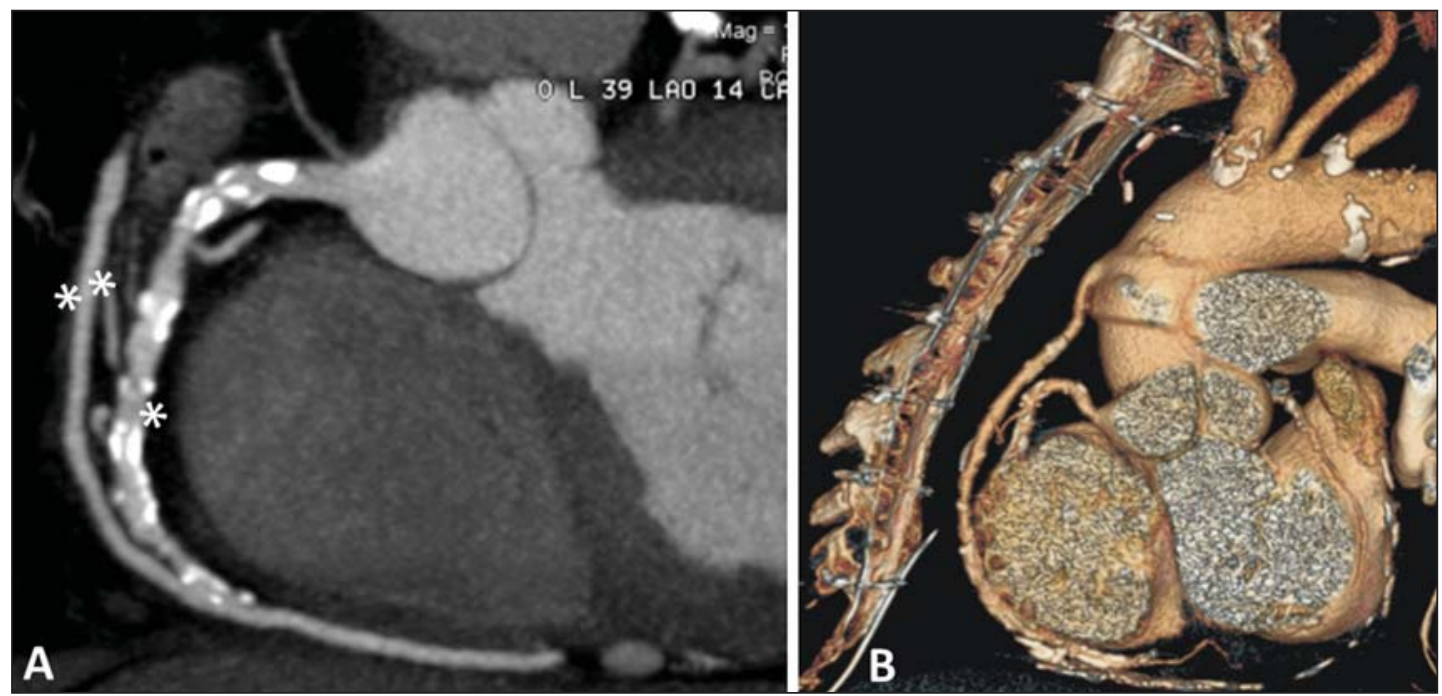

Figure 8. Evaluation of vena saphena graft to right coronary artery. Note the permeable graft (double asterisks) and the anastomosis with the right coronary artery (single asterisk) (A). 3D reconstruction (B).

be adopted, including a good hydration of the patient previously to the scan and use of acetylcysteine in the previous and in the following days, although studies evaluating such measures still remain controversial ${ }^{(8)}$.

\section{Future prospects}

CMRI as well as CCTA are diagnostic imaging methods undergoing constant technological development.

\section{Technological development of CMRI}

The main future prospect for CMRI is related to the continuous improvement of the images quality, allowing for a more detailed understanding of the myocardial anatomy, function and perfusion, of the tissues characterization and cardiac viability, besides representing an important tool for clinicians and cardiologists ${ }^{(40)}$. Undoubtedly this will reduce the acquisition time and will maintain or improve the diagnostic potential of the method.

\section{Technological development of CCT}

The main prospects for CCT involve the reduction of the radiation dose affecting the patient, reduction of the acquisition time and, consequently, of the breath hold time, reduction of the volume of contrast agent required for the noninvasive acquisition of coronary arteries images, and reduction of the radiation dose. Another prospect involves the analysis of myocardial perfusion by means of dual energy CT apparatuses ${ }^{(41-43)}$. The high spatial and temporal resolution of this method allows for images acquisition with a great anatomical detailing and noninvasive evaluation of the spatial relation between adjacent structures ${ }^{(26)}$.

\section{Anatomy versus ischemia / coronary flow reserve}

Over the last four decades, the analysis of the coronary anatomy to predict the myocardial physiological status has ever been considered to be evidencing. However, it is currently believed that the isolated anatomical analysis cannot predict the physiological behavior of a single patient, since the biological variability is not taken into consideration. Anatomical parameters such as percentage of stenosis in the coronary diameter are not a very useful tool to understand the physiological behavior in general. In the future, the tendency is the adoption of parameters capable of more accurately and less invasively predicting the physiological status.

Such physiological parameters can be evaluated by means of noninvasive imaging methods such as PET/CT or by invasive methods such as cardiac catheterization and, recently, noninvasively by CCTA. PET/CT, because of its high spatial resolution, is capable of quantifying myocardial perfusion at rest and stress and determining the coronary flow reserve. Cardiac catheterization allows for determining the fractional flow reserve that is defined as the quotient between the pressure distal to a stenosis and the proximal pressure. Both physiological parameters allow for more accurately predicting the degree of ischemia caused by the CAD, because these parameters are superior to evaluate diffuse, multisegmental coronary diseases and those with heterogeneous remodelling. As compared with each other, the coronary flow reserve is accurate to predict ischemia and superior in the evaluation of diffuse diseases, so there is a future tendency towards the analysis of such parameter by PET/CT. The most relevant PET/CT clinical application in myocardial perfusion is the selection of patients with atherosclerosis who will benefit more from undergoing myocardial revascularization ${ }^{(44)}$. The calculation of the fractional flow reserve has also been studied by means of CCTA. Although still undergoing improvements, it would be theoretically ideal for the management of patients with $\mathrm{CAD}$, since a single scan would allow for the anatomical evaluation of a determined stenosis and its functional, demonstrating if, in fact, there was impairment of the myocardium. However, data about clinical validation and cost-effectiveness are still limited ${ }^{(45,46)}$.

Another approach under study is the evaluation of myocardial perfusion under stress by CT in association with 
CCTA. Such a technique evaluates the myocardial perfusion um stress and the coronary anatomy, providing data about a possible ischemia and coronary stenosis, thus evaluating both the myocardial anatomy and physiology. Since 1970, there have been attempts to improve such technique, but only recently, with the technological evolution of CCT, it was possible to perform a myocardial evaluation under stress. Preliminary studies have demonstrated an improvement in the diagnostic accuracy when the techniques are utilized in combination as compared with CCTA alone. However, this technique still lacks further studies to establish imaging protocols defining contrast agents and radiation doses ${ }^{(47-50)}$.

\section{CONCLUSION}

CMRI and CCT are validated as highly sensitive and specific diagnostic tools, with few contraindications and minimal risks of adverse effects, and should be utilized by physicians as aid in the management of their patients.

\section{REFERENCES}

1. Carvalho ACC, Sousa JMA. Cardiopatia isquêmica. Rev Bras Hipertens. 2001;8:297-305.

2. Manfroi WC, Freitas FM, Gensini G, et al. Achados hemodinâmicos e cineangiocoronariográficos em pacientes acometidos de infarto do miocárdio: estudo comparativo entre uma população de Syracuse, NY, USA, com outra de Porto Alegre, RS, Brasil. Arq Bras Cardiol. 1980;34:359-62.

3. Behar S, Reicher-Reiss H, Abinader E, et al. The prognostic significance of angina pectoris preceding the occurrence of a first acute myocardial infarction in 4166 consecutive hospitalized patients. Am Heart J. 1992;123:1481-6.

4. Manfroi WC, Peukert C, Berti CB, et al. Infarto agudo do miocárdio. Primeira manifestação da cardiopatia isquêmica e relação com fatores de risco. Arq Bras Cardiol. 2002;78:388-91.

5. Zaslavsky C, Gus I. Idoso. Doença cardíaca e comorbidades. Arq Bras Cardiol. 2002;79:635-9.

6. Yu PC, Caramelli B, Calderaro D. Performance diagnóstica de angiografia coronariana por tomografia computadorizada de 64 detectores (estudo CORE 64). Rev Assoc Med Bras. 2009;55:235-6.

7. Berman DS, Hachamovitch R, Shaw LJ, et al. Roles of nuclear cardiology, cardiac computed tomography, and cardiac magnetic resonance: assessment of patients with suspected coronary artery disease. J Nucl Med. 2006;47:74-82.

8. Rochitte CE, Pinto IMF, Fernandes JL, et al. I Diretriz de Ressonância e Tomografia Cardiovascular da Sociedade Brasileira de Cardiologia - Sumário executivo. Arq Bras Cardiol. 2006;87:e48-e59.

9. Schuijf JD, Bax JJ, Shaw LJ, et al. Meta-analysis of comparative diagnostic performance of magnetic resonance imaging and multislice computed tomography for noninvasive coronary angiography. Am Heart J. 2006;151:404-11.

10. Pletcher MJ, Tice JA, Pignone M, et al. Using the coronary artery calcium score to predict coronary heart disease events: a systematic review and meta-analysis. Arch Intern Med. 2004;164:1285-92.

11. Nayler GL, Firmin DN, Longmore DB. Blood flow imaging by cine magnetic resonance. J Comput Assist Tomogr. 1986;10:715-22.

12. Helbing WA, Rebergen SA, Maliepaard C, et al. Quantification of right ventricular function with magnetic resonance imaging in children with normal hearts and with congenital heart disease. Am Heart J. 1995;130:828-37.

13. Hoffmann R, von Bardeleben S, Kasprzak JD, et al. Analysis of regional left ventricular function by cineventriculography, cardiac magnetic resonance imaging, and unenhanced and contrast-en- hanced echocardiography: a multicenter comparison of methods. J Am Coll Cardiol. 2006;47:121-8.

14. Versteegh MI, Lamb HJ, Bax JJ, et al. MRI evaluation of left ventricular function in anterior $\mathrm{LV}$ aneurysms before and after surgical resection. Eur J Cardiothorac Surg. 2003;23:609-13.

15. Rajiah P, Desai MY, Kwon D, et al. MR imaging of myocardial infarction. Radiographics. 2013;33:1383-412.

16. Nagel E, Lehmkuhl HB, Bocksch W, et al. Noninvasive diagnosis of ischemia-induced wall motion abnormalities with the use of highdose dobutamine stress MRI: comparison with dobutamine stress echocardiography. Circulation. 1999;99:763-70.

17. Nagel E, Klein C, Paetsch I, et al. Magnetic resonance perfusion measurements for the noninvasive detection of coronary artery disease. Circulation. 2003;108:432-7.

18. Schwitter J, Nanz D, Kneifel S, et al. Assessment of myocardial perfusion in coronary artery disease by magnetic resonance: a comparison with positron emission tomography and coronary angiography. Circulation. 2001;103:2230-5.

19. Barranhas AD, Santos AASMD, Coelho-Filho OR, et al. Cardiac magnetic resonance imaging in clinical practice. Radiol Bras. 2014; 47:1-8.

20. Hundley WG, Morgan TM, Neagle CM, et al. Magnetic resonance imaging determination of cardiac prognosis. Circulation. 2002;106: 2328-33.

21. Kim RJ, Wu E, Rafael A, et al. The use of contrast-enhanced magnetic resonance imaging to identify reversible myocardial dysfunction. N Engl J Med. 2000;343:1445-53.

22. Budoff MJ, Achenbach S, Duerinckx A. Clinical utility of computed tomography and magnetic resonance techniques for noninvasive coronary angiography. J Am Coll Cardiol. 2003;42:1867-78.

23. Maintz D, Ozgun M, Hoffmeier A, et al. Whole-heart coronary magnetic resonance angiography: value for the detection of coronary artery stenoses in comparison to multislice computed tomography angiography. Acta Radiol. 2007;48:967-73.

24. Leite CC. Gadolínio e fibrose nefrogênica sistêmica: o que todo médico deve saber. Radiol Bras. 2007;40(4):iv-v.

25. Gusso S, Salvador C, Hofman P, et al. Design and testing of an MRI-compatible cycle ergometer for non-invasive cardiac assessments during exercise. Biomed Eng Online. 2012;11:13.

26. Shiozaki AA, Jasinowodolinski D, Sara L, et al. Ressonância magnética cardiovascular e tomografia computadorizada cardiovascular nas doenças não-coronárias. Rev Soc Cardiol Estado de São Paulo. 2009; 19:348-60.

27. Bocchi EA, Marcondes-Braga FG, Ayub-Ferreira SM, et al. Sociedade Brasileira de Cardiologia. III Diretriz brasileira de insuficiência cardíaca crônica. Arq Bras Cardiol. 2009;93(1 supl 1):3-70.

28. Greenland P, Bonow RO, Brundage BH, et al. ACCF/AHA 2007 clinical expert consensus document on coronary artery calcium scoring by computed tomography in global cardiovascular risk assessment and in evaluation of patients with chest pain: a report of the American College of Cardiology Foundation Clinical Expert Consensus Task Force (ACCF/AHA Writing Committee to Update the 2000 Expert Consensus Document on Electron Beam Computed Tomography). Circulation. 2007;115:402-26.

29. Taylor AJ, Bindeman J, Feuerstein I, et al. Coronary calcium independently predicts incident premature coronary heart disease over measured cardiovascular risk factors: mean three-year outcomes in the Prospective Army Coronary Calcium (PACC) project. J Am Coll Cardiol. 2005;46:807-14.

30. Kronmal RA, McClelland RL, Detrano R, et al. Risk factors for the progression of coronary artery calcification in asymptomatic subjects: results from the Multi-Ethnic Study of Atherosclerosis (MESA). Circulation. 2007;115:2722-30.

31. Feldman CJ, Yordi LM. Imagem na cardiomiopatia isquêmica. Tomografia computadorizada de coronárias. Rev Soc Cardiol Rio Grande do Sul. 2009;XVII:1-6. 
32. Wexler L, Brundage B, Crouse J, et al. Coronary artery calcification pathophysiology, epidemiology, imaging methods, and clinical implications. A statement for health professionals from the American Heart Association. Writing Group. Circulation. 1996;94:1175-92.

33. Greenland P, LaBree L, Azen SP, et al. Coronary artery calcium score combined with Framingham score for risk prediction in asymptomatic individuals. JAMA. 2004;291:210-5.

34. Nasir K, Michos ED, Blumenthal RS, et al. Detection of high risk young adults and women by coronary calcium and National Cholesterol Education Program Panel III guidelines. J Am Coll Cardiol. 2005;46:1931-6.

35. McClelland RL, Chung H, Detrano R, et al. Distribution of coronary artery calcium by race, gender, and age: results from the MultiEthnic Study of Atherosclerosis (MESA). Circulation. 2006;1 13 30-7.

36. Gaspar T, Halon DA, Lewis BS, et al. Diagnosis of coronary instent restenosis with multidetector row spiral computed tomography. J Am Coll Cardiol. 2005;46:1573-9.

37. Cademartiri F, Mollet N, Lemos PA, et al. Usefulness of multislice computed tomographic coronary angiography to assess in-stent restenosis. Am J Cardiol. 2005;96:799-802.

38. Cury RC, Pomerantsev EV, Ferencik M, et al. Comparison of the degree of coronary stenoses by multidetector computed tomography versus by quantitative coronary angiography. Am J Cardiol. $2005 ; 86: 784-7$.

39. Moselewski F, Ropers D, Pohle K, et al. Comparison of measurement of cross-sectional coronary atherosclerotic plaque and vessel areas by 16-slice multidetector computed tomography versus intravascular ultrasound. Am J Cardiol. 2004;94:1294-7.

40. Vitorino RR, Nacif MS. Ressonância magnética cardíaca na cardiomiopatia dilatada: atualidades. Rev Bras Clin Med. São Paulo. $2011 ; 9: 225-33$.

41. Pinto IMF, Sousa AGMR, Ishikawa W, et al. Ressonância magné- tica e tomografia computadorizada no diagnóstico de insuficiência coronária. Rev Bras Cardiol Invas. 2006;14:168-77.

42. Parga Filho JR, Lima CSLM, Lima FG, et al. Perfusão miocárdica dinâmica por tomografia computadorizada de dupla fonte de raio X. Arq Bras Cardiol. 2012;98,54-8.

43. Delgado C, Vázquez M, Oca R, et al. Myocardial ischemia evaluation with dual-source computed tomography: comparison with magnetic resonance imaging. Rev Esp Cardiol (Engl Ed). 2013;66: 864-70.

44. Gould KL, Johnson NP, Bateman TM, et al. Anatomic versus physiologic assessment of coronary artery disease. Role of coronary flow reserve, fractional flow reserve, and positron emission tomography imaging in revascularization decision-making. J Am Coll Cardiol. 2013;62:1639-53.

45. Yoon YE, Koo BK. Non-invasive functional assessment using computed tomography: when will they be ready for clinical use? Cardiovasc Diagn Ther. 2012;2:106-12.

46. Nørgaard BL, Leipsic J, Gaur S, et al. Diagnostic performance of non-invasive fractional flow reserve derived from coronary CT angiography in suspected coronary artery disease: The NXT trial. J Am Coll Cardiol. 2014;63:1145-55.

47. Rossi A, Merkus D, Klotz E, et al. Stress myocardial perfusion im aging with multidetector CT. Radiology. 2014;270:25-46.

48. Johnson NP, Kirkeeide RL, Gould KL. Coronary anatomy to predict physiology: fundamental limits. Circ Cardiovasc Imaging. $2013 ; 6: 817-32$.

49. Sociedade Brasileira de Cardiologia. Diretrizes de doença coronariana crônica - angina estável. Arq Bras Cardiol. 2004;83(supl II): 143.

50. Mollet NR, Cademartiri F, Nieman K, et al. Multislice spiral computed tomography coronary angiography in patients with stable angina pectoris. J Am Coll Cardiol. 2004;43:2265-70. 